\title{
The Power of Online Marketing for Hospitality in Vietnam in Globalization Context
}

\author{
Dr. Van Ha Nguyen ${ }^{1},{ }^{2, *}$ \\ ${ }^{1}$ Faculty of Business Administration, Banking Academy, Hanoi, Vietnam \\ ${ }^{2}$ Faculty of Business Administration, Orleans University, Orleans, France
}

\begin{abstract}
Information technology and electronics have commercialized manufacturing activities and marketing, which creates opportunities for all of enterprises in developing new customers, new markets and inducing a rapid growth. However; it also places a challenge for firms to compete with their rivals while in an open market there are strong competitors domestically and overseas. Tourism in Vietnam is in need of making the full use of online marketing tools in the situation that the number of overseas tourists is on the rise. Each organization, each hotel must use online marketing in which way to create its own competitive advantage?

Researchers have shown that in every decision making process, the customers always go under the affect of various factors. Price, promotion, processing speed and response time, customers' rating of the hotels etc are among the key factors which are going to be looked into in this article.

The research has a scope of surveys in Hanoi, therefore it is not able to summarize the whole overseas tourists situation in Vietnam. Nevertheless, it serves as the grounds for travel agencies, hotels to testify their online marketing activities and consider the findings of this paper as reference for further deep research with different objectives
\end{abstract}

Key words: ICT (information and communication technology), OTAs ( online travel agency ), factor, influence.

\section{Introduction}

Globalization has opened a new door for e-marketing. Just with a few years, the advance of technology facilitating online marketing activities has contributed to Vietnamese tourism and helped change the face of hospitality industry.

Until 2010, the number of inbound tourists in Vietnam had reached 5.049.855, whereas 6.847.678 in 2012. During the first few months of 2013, the figure has swollen, as in the first quarter; it grew by $36.2 \%$ compared to the same quarter in 2009. The total revenue from tourism activities was also on the rise, from 96 thousand billions (2010) 160 thousand billions (2012). The role of tourism in Vietnamese economy has proven to be increasingly significant, with the majority of revenue comes from inbound tourists. According to the statistics from Google.com, until March of 2014, on average there are more than 57 million searches on the website Google.com with the key words: "Hotel in Hanoi". Summer is viewed as the low season for inbound tourism but the quantity of travelers in the first six months still witnessed a growth of around $32 \%$. Among those, more than $90 \%$ of inbound tourists had looked for information about their upcoming destination and the majority of them decided to book rooms and other services online.

Several tourism organizations are still trying to participate in classes to sharpen their abilities to provide online services and to gain trust from the public. The volume of website visitors cannot reflect the success since bringing more and more customers to the website is just the beginning, not the end of the process. Winning is not only about attracting more visitors, but also providing information about the hotel, retaining customers, boosting online reservations or using any services which generate revenue for the hotel.

A good sign indicates that there are more than $90 \%$ of the total people asked looked for information from different sources and from at least 2 websites. It means that consumers are reliable to change their mind. 
Therefore, the underlying issue here is to define which factors impact on the decision of online booking? How can companies and organizations do to promote their online marketing strategy to bring about the best outcome?

\section{Literature review}

\subsection{Hospitality}

\subsubsection{Definition}

- Hotel: Hotel is a commercial establishment providing lodging, which assures the quality and facilities needed for lodging and meet the requirements of staying, meals, entertainment and other guest services during the customers' stay in the hotel, appropriate with the purpose of the trip.

- Online Marketing: Online marketing is the application of information technology, digital media in market research, product development, marketing strategy and tactics.

Online marketing is not simply advertising or selling products and services though the internet but the integration of activities with the final objective is to effectively \& quickly bring the products and services to the consumers. Effective online marketing is to differentiate the company from their competitors and to make the customers choose to use the services.

\subsubsection{Hotel reservation}

The way in which the hotel introduces themselves to international visitors and sells rooms:

- Introduce and sell rooms directly on the hotel's website

- Introduce and sell rooms through worldwide booking pages: Booking.com, Agoda.com, Expedia, Hostelworld, etc.

- Use other tools: facebook, twitter, google+, etc.

- Website: not only hotels but also most of enterprises decide to build their own website. Website is the face of the hotel as well as an advertising medium providing adequate information. Technology advancement has helped hotels to make reservations on the website for their customers.

- Online booking sites (OTAs): booking, agoda, expedia, hostelworld, etc. are known as the sites providing lists of hotels in each area, cities around most of the countries for international tourists to find and choose from.

\subsection{Customer behavior}

\subsubsection{Decision-making process}

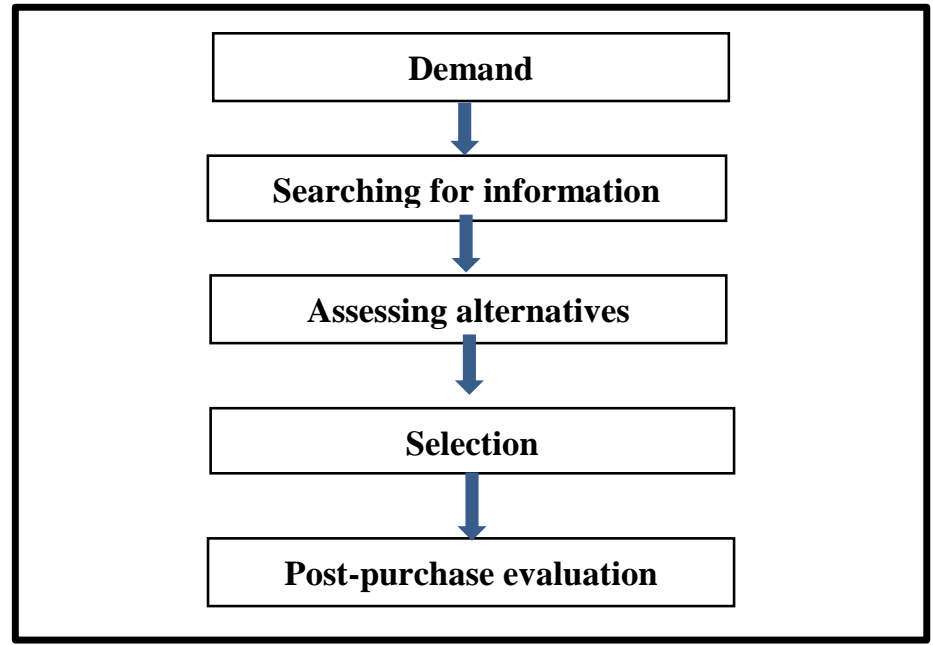

Fig. 1: Decision-making process

(Source: Marketing textbook - National Economics University) 


\subsubsection{Customer behavior}

- Demand: Demand is the want of individuals, groups or organizations, which can be tangible or intangible. When the customers have a strong demand, they will look for relevant information about the products or services.

- Information searching: Searching for the supply chain or the procedure to meet the demand. The customer can opt to these following basic sources:

- From individuals: family, friends, neighbors, etc.

- Commercialized information: trade events, exhibitions, advertising, sales staff, etc.

- Public information: advertising materials, public opinion, etc.

- Experience, sampling, testing, etc.

The degree of impact of above information sources changes depending on the type of product and customer characteristics. The result of gathering information is that the client obtains a "brand collection" of products. The marketers' aim is to provide information to sustain attention and respond consumers' needs, so that afterwards, their hotel will be included in the assessment group.

- Assessing alternatives: any field of business consist various suppliers; therefore, it is a benefit for consumers to choose from and consider. Customers mostly have their own criteria and requirements while searching for a supplier. When evaluating relatively competitive brands, the consumer's point of view can be based on some basic tendencies.

- Based on the product attributes

- Classification of level of importance of the attributes

- Building trust associated with the brand

According to Butterworth and the other authors in "Marketing in travel and tourism" (2009), the factors affecting demand and the decision on the hotel of the tourists include:

$\checkmark$ Economic factors and price

$\checkmark$ Demographic characteristics of visitors

$\checkmark$ Geographic factors

$\checkmark$ Socio-cultural factors of the destination

$\checkmark$ Infrastructure of the destination and neighbor attractions

$\checkmark$ Media

$\checkmark$ Information technology and techniques

- Buying decision: At the end of evaluation period of alternatives, the consumer can gather groups of suppliers sorted by criteria. The intention to buy is not always reliable because the buying decision is also subject to constraining factors.

- Post-purchase evaluation: post-purchase satisfaction or dissatisfaction will affect the following buying behavior of the consumer. High satisfaction happens when the product meets the expectation and desires of the consumer. Satisfaction or dissatisfaction of consumers will influence their attitude when there is a demand for repeating purchases and dissemination of the product's information.

\subsection{Methodology}

- The research was conducted over 2 phases. During the first stage, the author carried out preliminary interviews about demand for traveling as well as accommodation of inbound tourists, and the evolving issues around their traveling habits to foreign countries, especially to Vietnam. The central concern was the chosen accommodation in the desired destination. What determines the choice of guest accommodation, the issues or elements revolve around the accommodation. This preliminary interview process supported the author in completing the quantitative survey in the second stage. During the latter phase, the author performed in-depth interviews with questions designed and edited based on the preliminary interviews. The target number of 
participants was 200 people, including 184 people with valid samples. The samples were taken according to convenient sampling method, with $100 \%$ of total samples were foreign tourists traveling in Vietnam ( in particular: Hanoi), staying in hotels in Hoan Kiem District area and were in need of finding a hotel for the next destinations after leaving Hanoi.

- Behaviors of online decisions not only depend on the elements belonging to personal nature, but also the company's ability to meet the requirements of guests. Ignoring the personal preference, the paper will focus on investigating the objectives factors that organizations and hotels are able to control with their service quality and marketing strategies.

\section{The Research Findings:}

\subsection{The process of searching for and selecting hotels of tourists before traveling}

After carrying out in-depth interviews with a type of typical tourists: 30 people from many nations: Australia, Japan, France, U.K, U.S, Canada, Germany, Myanmar, etc. in order study the process of choosing a hotel of tourists. The final outcomes have been generalized into two processes.

\subsubsection{Process 1}

Choosing a hotel without any advice or information from relatives and friends:

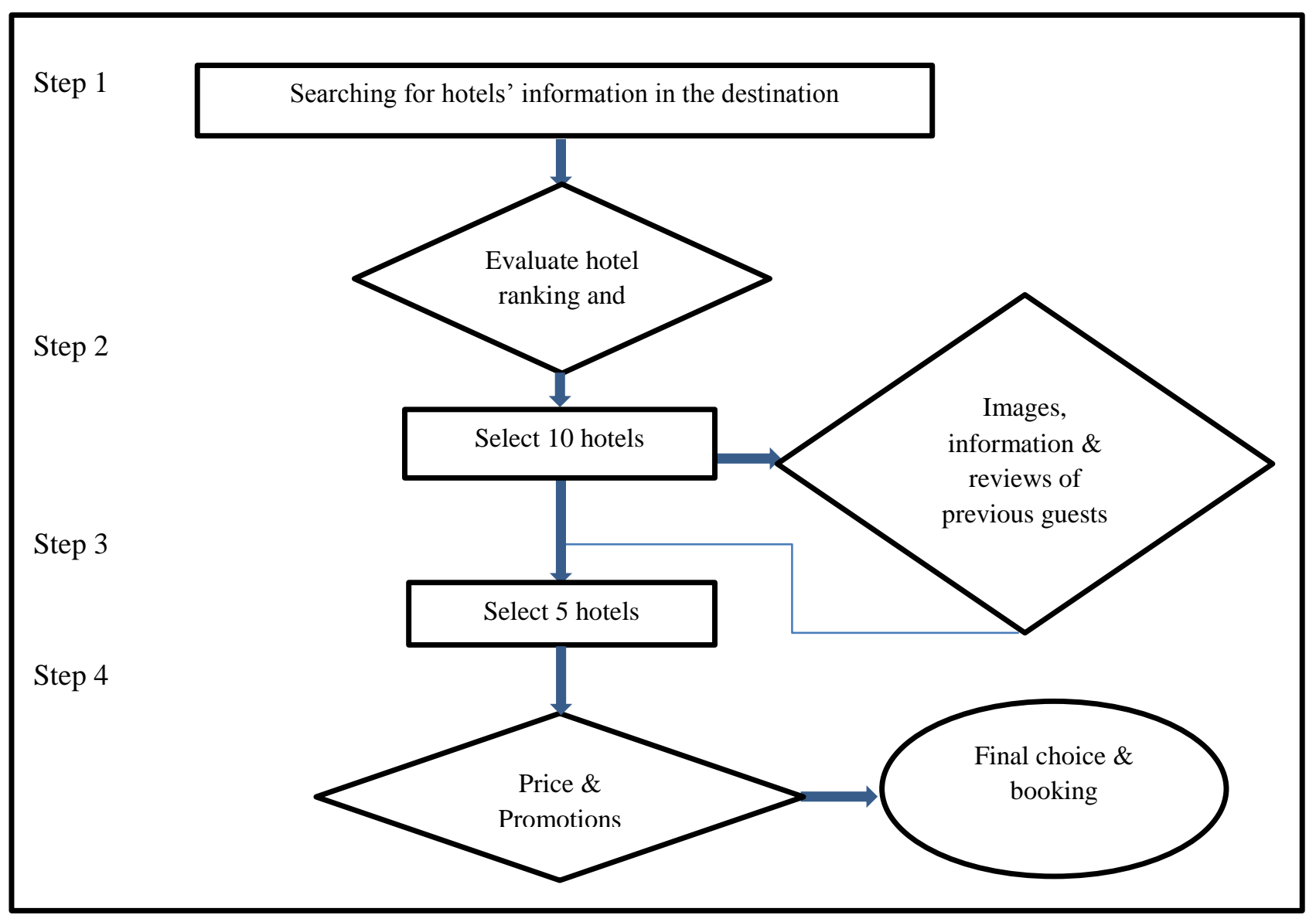

Diagram 1: The process of selecting a hotel 1

( Sources of information may include: Online travel and agencies websites, hotel websites, tripadvisors, etc. ) 


\subsubsection{Process 2}

This is the process in which tourists already knew about the some hotels suggested by their friends and relatives.

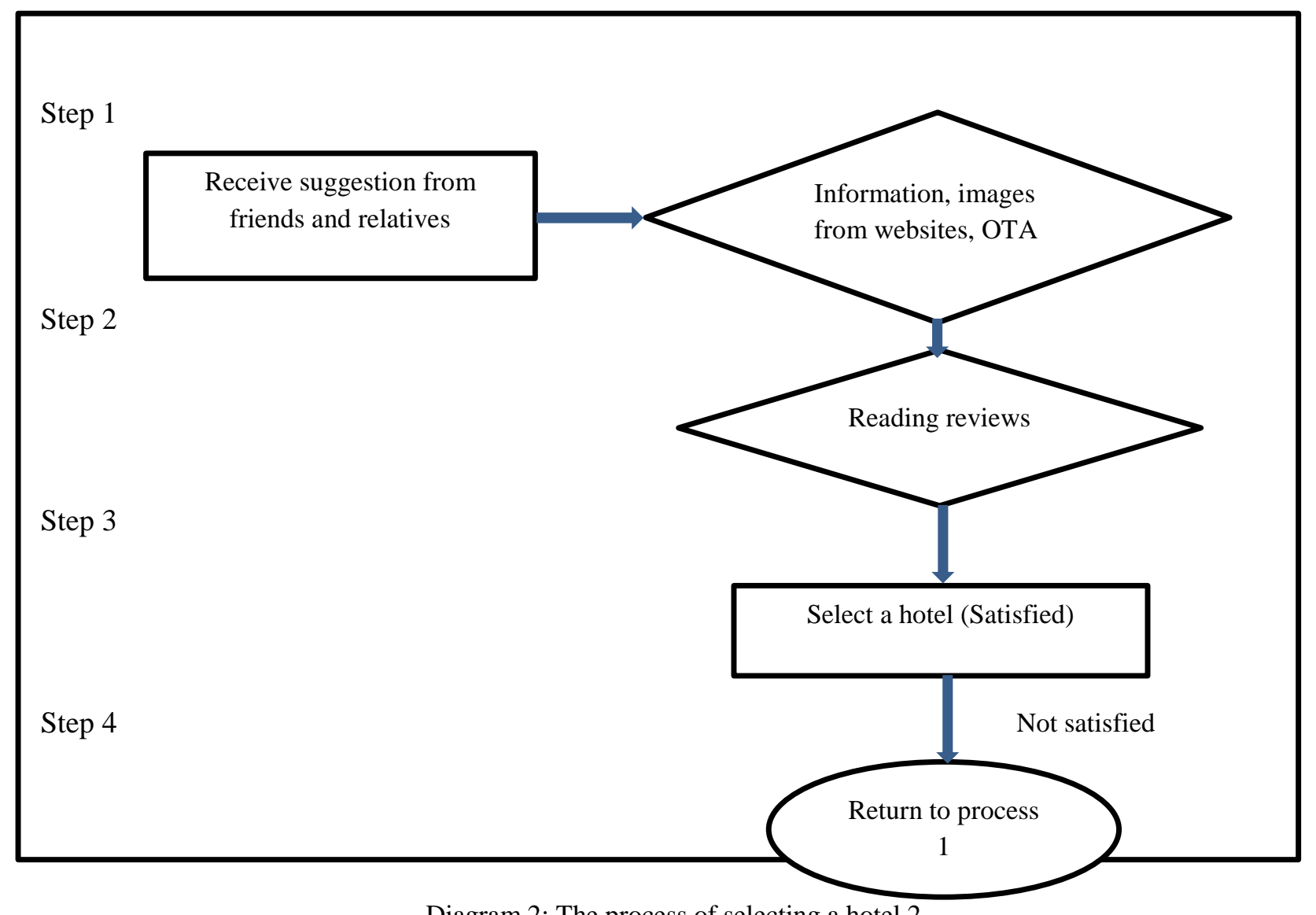

Diagram 2: The process of selecting a hotel 2

\subsection{Factors influence the booking decisions:}

\subsubsection{Marketing 4P and customers}

4P in marketing are: Products, Price, Place and Promotion. However, to be specific in the hospitality field, they are:

- The pricing factors: Price is relatively competitive among hotels; the importance of price in comparison with other factors

- The product attributes factors: Room services: size of the room, interior facilities, windows, balcony, etc; other services: airport transfer, breakfast, laundries, elevators, etc; feedbacks from previous guests and response from managers

- Other influencing factors: Place; promotion; ratings and distinctive strategies from competitors

\subsubsection{Synthetic results}

$>$ The target of the research

- Among the 184 samples, tourists come from many countries in the whole world, of four continents Asia, Europe, America and Oceania

- $75 \%$ of the interviewees' age are under $30,16.8 \%$ are from 30 to 60 and $8.2 \%$ are over 60 . The main tourists group traveling to Vietnam is within the age of 20 to 40, this group consists of youngsters, fond of exploring and traveling around the world. 
- Among the respondents, there were $34.8 \%$ people asked traveled with friends, $27.2 \%$ travelers are solo, whereas $24.4 \%$ tourists traveled with family and the others (13.6\%) are couples. It can be seen from the statistics that there is no big difference among the types of travel of inbound tourists. In this research, the rate of tourists traveling alone was noticeably high, only after that of who traveled with friends. It is because of their nature, as being free and independent. The result of in-depth interviews with a group in the research pointed out that foreign tourists cared more about their individual needs, travel is one of those needs and they would even travel without their fellow travelers. They also have a tendency of making new friends on the way.

\section{$>$ Booking conditions and methods}

- Ways of searching for booking information:

- Approximately $64.47 \%$ of tourists use social networks, online booking websites to seek for information needed. This is an easy and convenient way, popular among them. Those online booking websites can provide lists of hotels at the destination.

- $\quad 32.07 \%$ respondents answered that they asked friends and relatives for more suggested attractions. These recommendations would help them in their preliminary decisions.

- A very small amount, 3.27\% of people asked replied that they did not search for information in advance. This group of tourists has the customs of direct searching and selecting accommodation on their arrival, and they mainly looked for the cheap ones.

- Booking conditions.

- The majority of the answers were booking online, with more than $29 \%$ always had that habit. Up to $85 \%$ guests booked for a room online and the rests used direct contact via phone and email.

\section{Key factors affect the booking decisions}

- Factors are listed from the most to the least ones: Price; Hotel services; Feedbacks, evaluations from customers; Hotel ranking; Promotions

\section{$>$ Tangible aspects}

- A group of questions of (as question 9) in the survey evaluated the tangible prospects of the hotel services. There are three issues that tourists care about and search for the hotel, including: Facilities within the rooms; nline images of the rooms and serving services for breakfasts, tea, coffee

- $72.3 \%$ tourists cared about the hotel images, while $81.5 \%$ paid attention to the amenities, and more than $90 \%$ interested in services like free breakfasts, tea, coffee.

- Less important factor to tourists was the elevators of the hotel. More than $60 \%$ answered whether the hotel had or did not has the elevators was not of their concern Those hotels did not have an elevator were mostly have less than 7 floors, for those above 8 floors are all well-equipped. The majority of tourists over 50 years old tended to like to walk, and not paying much concern about the elevators. Many people told that they could walk for $40 \mathrm{~km}$ per day and a group of customers said that they preferred the stair ways.

- Factors: Room area (room's squares), room with balcony or windows, taxi pickup or transfer, shared fairly percentages of concern with 50\% cared about and 50\% did not.

\section{$>$ Intangible aspects}

- Feedbacks from customers: among 184 interviewees, $83.6 \%$ believed that reviews from previous guests were important, that was the basis for them to choose or evaluate the hotel. Most of the tourists read the comments before deciding whether to book or not. Besides, they would also read the 6-15 most recent reviews.

- A question was how the manager's response was viewed by tourists? $62.9 \%$ said that those responses showed a good attitude, which might impress them with the hotels. Their replies meant that they cared about their customers' feelings and would like to try to advance their services. Most of the tourists agreed that manager should really have answers for the customers' reviews. 


\subsubsection{Proposals:}

Key factors shall affect the tourists' decision making are among four familiar Ps. What do your hotel get? Good prices? Good location? Good rank? Are being more popular among tourists, receiving many compliments and good reviews (Public Relations) or know how to grasp and build advertising strategies? Understanding the company/organization's S.W.O.T (strengths, weaknesses, opportunities and threats) and targeting appropriate customers with those S.W.O.T are the key success factors for all organizations.

\section{Pricing strategies}

- The low season is from May to July for tourists coming to Vietnam, so the pricing strategies must be different from the high season from October to December. The new fare level should be based on the changes of similar competitors and avoid too high price that cannot attract many tourists nor too low, which would affect the hotel's benefits.

- Pricing strategies for each period should be flexible for each day, each specific situations for different tourists.

\section{$>$ Promotion policies}

- Promotion programs are familiar strategies for all companies, organizations.

Some effective promotion campaigns for customers are: early booking, long-staying or last-minute booking? These would stimulate customers who care more about reducing price. Those events need to consider the minimum price basis and maintain hotel operations.

- Special promotion can help differentiate the organization from other competitors and enhance competitiveness. Developing promotional packages: giving out movie tickets, water puppet tickets, free airport transfer for long-staying customers, special treatments for honeymoon couples... The promotions need to impact on customers' wants and needs, whereas unique and contain special meaning. Besides, the processing speed and information transmission about the promotions should be as fast as possible.

\section{Service quality assurance}

- Tourists' satisfaction is evaluated on all of the online booking sites or hotel websites. At the same time, they will spread out positive word-of-mouth to their friends and relatives about places they like. Hotels that have good feedbacks would be rewarded with certificates on travel sites, books and become more competitive than other rivals. This is also the foundation to build a strong brand for the organization

\section{Hotels need to provide good services, reasonable price and satisfy the most of customers.}

- For each hotel, besides servicing and satisfying customers, the manager should be able manage reviews, comments from customers and their feedback of the hotel (both negative and positive ones). Also, replying all those reviews make the better impression on the hotel and demonstrate that the hotel pay attention to the tourists' feelings. Harmonizing all the strategies to attract foreign travelers to come to Vietnam is still a matter of all companies. All of the managers, marketing and online sale employees are trying to make their online marketing strategies the most effective.

\section{Conclusion}

With the purpose of identifying factors that influence the decision of selecting and booking hotel rooms of foreign tourists coming to Vietnam especially to Hanoi, the importance of tangible elements, the elements that create the value added for the hotel will affect the customers' decision.

The research results and statistics stated the role and benefits of effective online marketing. Many former research showed effective online marketing tools such as maximizing the searching for SEO tools, OTAs, building the connection among social networks, email marketing, renting the service advertisement... all help increase the influencing effects of hotels as well as increase the reservation numbers. However, the matter is that how to manage, apply and use those tools, to make a united and focusing result, to make the most effective 
business and minimize the budget. In addition, each hotel should understand clearly its own strengths and weaknesses in services, thus can build up its own business strategies. Understanding tangible and intangible values that the customers care about is a competitive advantage for each hotel in order to know what to do, will do and can do to survive and grow in a competitive business environment while the context of economic crisis can still affect the current situation.

\section{References}

[1] GS.TS. Tran Minh Dao (2012), Marketing căn bản, National Economics University Publication, Hanoi

[2] PGS.TS. Trương Đình Chiến (2011), Quản trị marketing, $1^{\text {st }}$ Edition, National Economics University Publication, Hanoi

[3] Dave Chaffey and PR Smith (2008), eMarketing eXcellence: Planning and optimizing your digital marketing,Butterworth-Heinemann is an imprint of Elsevier Linacre House, Jordan Hill, Oxford OX2 8DP, UK30 Corporate Drive, Burlington, MA 01803, USA; First published 2002, Copyright @ 2008, Dave Chaffey and PR Smith. All rights reserved

[4] Owen-Jones(2009),Marketing Communications in Tourism and Hospitality, Butterworth-Heinemann is an imprint of Elsevier Linacre House, Jordan Hill, Oxford OX2 8DP, UK The Boulevard, Langford Lane, Kidlington, Oxford OX5 1GB, UK; First edition 2009, Copyright (C) 2009 Elsevier Ltd. All rights reserved

[5] Victor T. C. Middleton, Alan Fyall and Michael Morgan, with contributions from Ashok Ranchhod (2009), Marketing in Travel and Tourism, Butterworth-Heinemann is an imprint of Elsevier Linacre House, Jordan Hill, Oxford OX2 8DP, UK30 Corporate Drive, Suite 400, Burlington, MA 01803, USA First published 1988, Copyright @ 2009 Elsevier Ltd. All rights reserved

[6] "Nghiên cứu các yếu tố ảnh hưởng đến sụ lưa chọn du lịch tại Huế của khách du lịch luu trú tại Ana Mandara Resort \& Spa Huế (2013), Available: http://thuvien24.com/nghien-cuu-cac-yeu-to-anh-huong-den-su-lua-chon-du-lich-tai-huecua-khach-du-lich-luu-tru-tai-ana-mandara-resort-spa-hue-55256.html 